\title{
Autosomal dominant severe congenital neutropenia
}

INSERM

\section{Source}

INSERM. (1999). Orphanet: an online rare disease and orphan drug data base. Autosomal dominant severe congenital neutropenia. ORPHA:486

Autosomal dominant severe congenital neutropenia is a rare primary immunodeficiency disorder characterized by autosomal dominant inheritance, absolute neutrophil counts below $0.5 \times 10 \mathrm{E} 9 / \mathrm{L}$ in the peripheral blood (on three separate occasions over a six month period), granulopoiesis maturation arrest at the promyelocyte/myelocyte stage and early-onset, severe, recurrent bacterial infections. 